\title{
Deber ético del radiólogo: Confidencialidad y secreto médico, respeto a la intimidad y dignidad del paciente.
}

\author{
Joaquín Hevia M.', Enrique Bosch $0 .^{2}$, Karla Moënne B.' ${ }^{2}$ Cristián García B. ${ }^{2}$
}

1. Director Zonal III y IV regiones, Sociedad Chilena de Radiología. Santiago, Chile.

2. Comité de Ética, Sociedad Chilena de Radiología. Santiago, Chile.

Radiologists' duties: Confidentiality and professional secrecy, respect for patients' dignity and intimacy.

\begin{abstract}
An ethical and professional medical behavior, which promotes and respects the ethical principles of medicine, is a goal that should always be pursued in medical practice. In radiology, as in other medical specialties, this includes respect for patients' dignity, intimacy and confidentiality. The possibility of accessing patients' private information compels radiologists to make a correct usage of this information, in order to respect professional secrecy and privacy codes that rule medical practice. Radiologists must teach and raise awareness among their students and co-workers in health care institutions of the importance of ethical behavior in their daily practice.
\end{abstract}

Keywords: Ethics, Radiology, Confidentiality, Physician-patient relations, Personhood.

Resumen. La práctica médica debe estar siempre enmarcada en un ejercicio profesional moralmente aceptable, que procure la promoción y respeto de los principios éticos fundamentales de la medicina, manteniendo el beneficio del paciente como objetivo principal. Al igual que otras especialidades, en el ejercicio de la radiología, se debe cuidar el marco ético profesional que obliga a velar por el respeto de la dignidad e intimidad de las personas y todo lo relacionado con la confidencialidad del acto médico. En el ejercicio de la radiología, al igual en que otros actos médicos, se tiene acceso a información sensible y privada de los pacientes, lo que obliga a hacer un correcto uso de ella, resguardando las normas de privacidad y secreto profesional. Se debe enseñar y sensibilizar a los alumnos y al personal que asiste en el cuidado de los pacientes, para asegurar un comportamiento acorde a las normas éticas que rigen la práctica radiológica.

Palabras clave: Ética, Radiología, Confidencialidad, Relaciones médico-paciente, Dignidad humana.

Hevia J., et al. Deber ético del radiólogo: Confidencialidad y secreto médico, respeto a la intimidad y dignidad del paciente. Rev Chil Radiol 2018; 24(1): 2-4.

Correspondencia: Joaquín Hevia M. / drjoaquinhevia@gmail.com

Trabajo enviado el 13 de abril de 2017. Aceptado para publicación el 27 de abril de 2017.

\section{Introducción}

Siguiendo con la serie de artículos relativos a los eventuales conflictos éticos que podemos estar expuestos como radiólogos, en esta oportunidad desarrollaremos la aplicación y vigencia del deber ético que existe respecto de la confidencialidad, la intimidad y dignidad del paciente, el secreto médico y el correcto uso de imágenes por parte del radiólogo.

Como ya ha sido mencionado, la práctica radiológica debe ser sometida a los principios fundamentales de la medicina, descritos por Beauchamp y Childress: respeto a la autonomía del paciente, no maleficencia, beneficencia y justicia. Junto con ellos, debemos incluir otros principios éticos tradicionales y principios relacionados a expectativas sociales, también relevantes al momento de tomar decisiones éticas en el contexto radiológico: prudencia, respeto a la intimidad y dignidad humana, confidencialidad, veracidad y honestidad.

El Colegio Interamericano de Radiología ha incluido en su código de ética, además de los principios fundamentales de la medicina, el respeto a la privacidad, entendido como la norma moral de mantener el secreto médico, para de esta manera diferenciarlo y destacarlo, por estar estrechamente relacionado a la práctica radiológica. 


\section{Respeto a la intimidad y dignidad humana}

En el contexto del principio de respeto de la intimidad se entiende que el cuerpo humano y sus partes deben ser tratados con especial cuidado y respeto. Tiene la condición de íntimo todo aquello que los seres humanos valoramos como privado y que por ello consideramos que no tiene por qué estar expuesto. El derecho a la intimidad es el derecho al control de los propios valores. Todo aquello que pertenece al ámbito de la intimidad tiene carácter confidencial.

La intimidad puede ser fácilmente vulnerada en nuestra práctica radiológica diaria si no se toman las medidas adecuadas para que esto no suceda. En toda circunstancia, independiente del estado de conciencia del paciente, es un deber ético respetar su pudor, intimidad y dignidad, evitando la exposición innecesaria de partes desnudas de su cuerpo en la adquisición de imágenes diagnósticas, en especial cuando hay otras personas en la sala de examen. Debemos ponernos siempre en el lugar del paciente y actuar de acuerdo a ese pensamiento.

Al realizar los estudios imagenológicos se puede caer en la despersonalización, donde el paciente pasa a ser una cosa o una enfermedad y no un ser humano en su totalidad, lo que puede resultar en un acto desmoralizante y ofensivo para la persona, atentando directamente contra su dignidad. Somos responsables de generar un entorno en el que todo el personal que atiende al paciente sienta el deber moral de entregar una atención humana y digna, enseñando además estos valores a nuestros alumnos. Esto es de tal relevancia dentro de los derechos de las personas que, junto con otros derechos fundamentales, ha sido reconocido en la Declaración Universal de los Derechos Humanos (1948).

\section{Secreto médico}

El secreto médico ha sido considerado como pilar fundamental de la ética médica desde tiempos de Hipócrates. Según dicta el Juramento Hipocrático: "Lo que en el tratamiento o incluso fuera de él, viere u oyere en relación con la vida de los hombres, aquello que jamás deba divulgarse, lo callaré teniéndolo por secreto", sigue siendo un tema de total vigencia y base de sustento de la relación médico-paciente. El código internacional de Ética Médica de la Asociación Médica Mundial refiere que "el médico debe guardar absoluto secreto de todo lo que se le haya confiado, incluso después de la muerte del paciente".

En el contexto de la relación médico-paciente, se puede considerar secreto todo lo que ha surgido de la interacción con el médico, incluyendo el hecho mismo de consultar. Es obligación ética del médico guardar reserva de los hechos conocidos por él en el ejercicio de la profesión, lo que con frecuencia no se cumple en las distintas especialidades médicas, incluida la radiología.
El secreto médico persigue resguardar la intimidad, algo propio y exclusivo de cada persona y no le corresponde al médico juzgar qué es lo íntimo o reservado en cada paciente. El paciente revela detalles de su intimidad más profunda al médico, con el convencimiento de que ello le permitirá a éste establecer sus conclusiones, con el fin último de la recuperación de su salud.

La práctica médica en Chile debe además someterse a las leyes vigentes, incluyendo la Ley de Derechos y Deberes de los pacientes (ley № 20.584), que menciona que se debe "respetar y proteger la vida privada y la honra de la persona durante su atención de salud". Se explicita también que la "información que surja tanto de la ficha clínica como de los estudios y demás documentos donde se registren procedimientos y tratamientos (...) será considerada como dato sensible, de conformidad con lo dispuesto en el artículo $2^{\circ}$ de la ley 19.628 ". Tanto la información personal del paciente como sus imágenes o archivos asociados (por ejemplo: epicrisis, orden médica u otros documentos que pueden ser asociados a la realización de un informe o adquisición de imágenes) son información sensible, debiendo ser resguardados en forma segura.

Hay algunas excepciones que permiten al médico saltarse esta obligación, debido a circunstancias que se anteponen al juramento hipocrático. Esto ocurre cuando (a) hay consentimiento del mismo paciente para revelar la información sanitaria, (b) hay grave peligro para el mismo paciente, otras personas 0 para la sociedad en general, (c) hay obligaciones penales y sanitarias a las que está sujeto el médico o (d) se considera el derecho de todo profesional a la propia defensa.

\section{Confidencialidad y uso ético de las imágenes y de la información del paciente}

La confidencialidad es un deber del profesional y un derecho del paciente. Implica que sólo las personas directamente involucradas en su atención tendrán acceso a su historial médico y estudios radiológicos y su uso estará sujeto a estrictas normas éticas y legales que prohíben su divulgación más amplia.

Del derecho a la intimidad surge la confidencialidad como valor y atributo de la información que contenga datos personales.

Como todo médico, los radiólogos tenemos una responsabilidad ética y legal respecto de la confidencialidad del paciente. Si bien la profundidad de la relación médico-paciente es mayor en el caso de los médicos clínicos, la obligación es la misma.

La relación radiólogo-paciente va desde interpretar una radiografía, donde generalmente no hay contacto directo con el paciente, hasta aquellos casos en que sí hay contacto, como puede ocurrir en una ecografía $\mathrm{o}$, en especial, en un procedimiento intervencional. 
En ambos casos, el derecho a la confidencialidad es el mismo.

Hoy en día, la mayoría de los centros hospitalarios de nuestro país cuenta con potentes sistemas de información que permiten adquirir, almacenar y transmitir imágenes digitales. Entre otros beneficios, esto ha facilitado enormemente el acceso en línea a la historia médica, diagnósticos clínicos, imágenes e informes radiológicos. Como consecuencia, somos parte de una nueva cultura de trabajo médico, con mayor rapidez en el traspaso de información y capacidad de acceder a ella en forma remota, pudiendo vulnerarse la seguridad, con la consecuente pérdida de la privacidad de la información.

Con esta tecnología, los médicos cuentan con acceso a información confidencial, incluso a distancia, y el secreto profesional puede perderse si el médico no tiene clara conciencia de su responsabilidad en el manejo de la información y respeto de la confidencialidad.

Debe asegurarse el carácter confidencial, seguridad y uso ético de la información personal contenida en las imágenes, informes radiológicos y el resto del historial médico. Esto incluye la publicación de imágenes en literatura médica, presentaciones y redes sociales, donde siempre se deberá asegurar la confidencialidad del paciente. No se viola el carácter confidencial cuando se transfiere información con fines de investigación científica, docente o en contexto de auditorías, siempre que la información entregada no revele de manera alguna la identidad del paciente. Para minimizar este riesgo, se han desarrollado herramientas computacionales que protegen y controlan el acceso a intranet y la descarga de imágenes, anonimizando las imágenes obtenidas.

\section{Conclusiones}

- Es deber de todo médico velar por que la práctica médica esté siempre enmarcada en un ejercicio profesional moralmente aceptable, que procure la promoción y respeto de los principios éticos fundamentales de la medicina en lo que se refiere a la relación con los pacientes.

- Al igual que otras especialidades, como radiólogos debemos actuar éticamente, respetando en especial el respeto a la dignidad e intimidad de los pacientes y todo lo relacionado con la confidencialidad del acto médico.

- En la práctica de la radiología debemos evitar la deshumanización y despersonalización al analizar los estudios imagenológicos. Es nuestra responsabilidad como radiólogos mantener el foco del quehacer diario centrado en el paciente.

- Los sistemas informáticos facilitan el acceso a información sensible y privada de los pacientes, lo que nos obliga a hacer uso de ellos bajo las normas de privacidad y secreto profesional que nos rigen.

- Las redes sociales y el acceso fácil a la información, deben ser manejados con especial cuidado, para resguardar la confidencialidad de nuestros pacientes.

- Debemos enseñar y sensibilizar a nuestros alumnos y al personal que nos acompaña en el cuidado de los pacientes, para lograr un comportamiento acorde a las normas éticas que nos rigen.

- Para cumplir con nuestra obligación moral como médicos en el trato del paciente y su información confidencial, debemos ponernos siempre en su lugar.

\section{Agradecimientos}

Agradecemos la colaboración del Dr. Gustavo Rencoret Silva.

\section{Lectura recomendada}

1. García C. ¿Está el radiólogo expuesto a conflictos éticos en su práctica diaria?. Rev Chil Radiol. 2017; 23: 46-47.

2. Armstrong JD. Morality, ethics, and radiologists' responsibilities. Am J Roentgenol. 1999; 173: 279-284.

3. Beauchamp TL, Childress J. Principles of Medical Ethics. 5th edition. Oxford Univ Press. 2001; 454.

4. Mir Tubau K, Busquets Alibés E. Principios de Ética Biomédica, de Tom L. Beauchamp y James F. Childress; . Bioètica \& Debat. 2011; 17:1-7.

5. Peralta A. Código de ética y deontología médica. Colegio Interamericano de Radiología. 2015; 3-4.

6. European Society of Radiology Code of Ethics. European Society of Radiology. 2013; 1-13.

7. American College of Radiology. 2017 - 2018 Bylaws. Article XI. 2017; 29-33.

8. Ministerio de Salud. Ley 20.584 - Ley de Deberes y Derechos de los pacientes. 2012; 1-6. 